\title{
Chronic sleep loss and risk-taking behavior: Does the origin of sleep loss matter?
}

Natalia Rusnac, Florence Spitzenstetter \& Patricia Tassi

To cite this article: Natalia Rusnac, Florence Spitzenstetter \& Patricia Tassi (2019) Chronic sleep loss and risk-taking behavior: Does the origin of sleep loss matter?, Behavioral Sleep Medicine,

17:6, 729-739, DOI: $10.1080 / 15402002.2018 .1483368$

To link to this article: https://doi.org/10.1080/15402002.2018.1483368

曲 Published online: 20 Jun 2018.

Submit your article to this journal $\mathbf{Z}$

W Article views: 246

Q View related articles 5

View Crossmark data

Citing articles: 1 View citing articles

Full Terms \& Conditions of access and use can be found at https://www.tandfonline.com/action/journalInformation?journalCode=hbsm 20 


\title{
Chronic sleep loss and risk-taking behavior: Does the origin of sleep loss matter?
}

\author{
Natalia Rusnac, Florence Spitzenstetter, and Patricia Tassi \\ Department of Psychology, University of Strasbourg, Strasbourg, France
}

\begin{abstract}
Background: Many adolescents and young adults get insufficient sleep. A link between sleep loss and risk-taking behavior has been consistently found in the literature, but surprisingly, the role played by the origin of sleep loss in this link has never been investigated. Sleep loss can be voluntary (instead of sleeping, a significant amount of time is devoted to other activities) or involuntary (caused by a sleep disorder, for example, insomnia). The aim of this research was to investigate whether both types of sleep loss are associated to the same extent with risky behavior. Participants: Five hundred thirty-six university students between 19 and 25 years old participated in this study. Three groups were selected: participants with voluntary sleep loss, participants with insomnia, and normal sleepers. Methods: We assessed risk-taking behavior in virtual driving situations, as well as drinking habits in terms of quantity and frequency. To further explore the differences between the groups, we also measured sensation seeking, a personality trait related to risk-taking behavior. Results: Compared to participants with insomnia and normal sleepers, participants with voluntary sleep loss take more risks in dangerous driving situations, drink more alcohol, and have higher disinhibition scores on the Sensation-Seeking Scale. On the other hand, no such differences were found between participants with insomnia and normal sleepers, suggesting that sleep loss is not always associated with risk taking. Conclusions: Whether sleep loss is associated with risk-taking behavior or not could depend on the origin of sleep loss and the underlying personality traits.
\end{abstract}

Numerous studies show that adolescents and young adults are often getting insufficient sleep (Carskadon, 1990; Gibson et al., 2006; Hysing, Pallesen, Stormark, Lundervold, \& Sivertsen, 2013; National Sleep Foundation, 2006; Roberts, Roberts, \& Xing, 2011; Strauch \& Meier, 1988; Wolfson \& Carskadon, 1998). There is also considerable evidence that links sleep loss to risk-taking behavior in young people (Carskadon, 1990; Catrett \& Gaultney, 2009; Dahl \& Lewin, 2002; O’Brien \& Mindell, 2005).

However, no study so far has investigated whether the origin of sleep loss influences this link. Sleep loss in young people can occur for various reasons, which may be classified in two categories: voluntary or involuntary (Catrett \& Gaultney, 2009). Voluntary sleep loss results from a lifestyle in which a significant amount of the time normally devoted to sleep is used for other activities. Instead of sleeping, some young people choose to spend more time studying, working, going out, playing video games, watching TV, surfing the Internet, and so forth (Carskadon, 1990; Millman, 2005). We will refer to this pattern of sleep loss as voluntary in the sense that it is not caused by a sleep disorder, but it is the result of a conscious choice to replace sleep with other activities (regardless of whether these activities pertain to work obligations or just leisure). Although the prevalence of voluntary sleep loss among young people is unknown, it is reasonable to assume that it has increased over the past years along with technological development. Many studies have demonstrated a link between the use of electronic devices and sleep deficit in young people (Hysing et al., 2015; Van den Bulck, 2007). 

On the other hand, sleep loss can be caused by sleep disorders, one of the most common being insomnia (Carskadon, 1990; Dahl \& Lewin, 2002; Vignau et al., 1997). We will refer to this type of sleep loss as involuntary in the sense that it does not result from a conscious choice of doing other activities late at night, but it is due to a sleep disorder that individuals have no or little control over.

Is sleep loss associated with risk-taking behavior regardless of whether sleep loss is voluntary or involuntary? The main goal of the present research was to answer this question. Thus, comparing participants with insomnia and participants with voluntary sleep loss may show whether the origin of sleep loss plays a role in this link. With regard to risk-taking behavior, we chose to measure specifically risky driving behavior and alcohol consumption for two reasons. Firstly, these behaviors are among the most common risky behaviors in the young population. Indeed, alcohol abuse in young people is a major public health problem (ESPAD, 2015). As to risky driving, it is well documented that road accidents have a significantly higher occurrence in young people in comparison to the older age groups (Deery, 1999). Secondly, both of these risky behaviors can have severe or even life-threatening consequences. Alcohol abuse can lead to ethylic coma, injury, violence, unsafe sexual behavior, and other such problems (Hingson, Heeren, Zakocs, Kopstein, \& Wechsler, 2002). Similarly, risky driving can have dangerous consequences. For instance, in France, young people aged between 18 and 24 represent $9 \%$ of the population but account for $26 \%$ of deadly road accidents (Assailly, 2001). Similar data have been reported in other countries (Deery, 1999). Therefore, investigating the link between sleep loss and these two risk-taking behaviors that are both common and dangerous may have real-life implications, particularly in terms of prevention campaigns.

To further explore the distinction between participants with insomnia and participants with voluntary sleep loss, we investigated whether these two groups differ in terms of sensation seeking. This personality trait refers to the tendency to seek novel, complex, and stimulating experiences (Zuckerman, 1994; Zuckerman, Kolin, Price, \& Zoob, 1964). Studies conducted in young people have consistently linked sensation seeking to risk taking, for example, in terms of alcohol abuse, risky driving, reckless sexual behavior, or extreme sports (Arnett, 1992; Ball, Carroll, \& Rounsaville, 1994; Zuckerman, 1994; Zuckerman \& Neeb, 1980).

Voluntary sleep loss could be seen as a risky behavior in itself. Young people may decrease sleep duration because they want to do more exciting things, to test and push their limits, or even to defy parental authority (Guénolé, Louis, \& Nicolas, 2008). It is therefore likely that individuals who delay bedtime in order to spend time on other activities have a higher propensity for sensation seeking. Reynolds et al. (2015), for instance, have shown that adolescents who perceive fewer negative consequences of risk-taking behaviors play video games till later at night compared to adolescents who perceive more negative consequences.

Thus we hypothesize that participants with voluntary sleep loss would have higher sensationseeking scores. We also expect that they would drink more alcohol and engage in greater risky driving behavior in comparison to individuals with insomnia and to normal sleepers.

\section{Materials and methods}

\section{Participants}

Participants were 536 university students ranging from 19 to 25 years old $(M=22.25$ years, $\mathrm{SD}=1.47,47.2 \%$ women). All participants had possessed their driving license for at least two years. The present study was approved by the Ethical Committee of the Faculty of Psychology of the university. All participants gave their informed consent and were paid for their participation.

To recruit participants, we e-mailed all the students of our university, asking them to reply if they were interested in taking part in a study investigating the impact of sleep loss on attention. Subsequently the responders were asked via e-mail a series of questions about their sleep, which allowed us to select the participants for each of the three groups. 
Participants included in the chronic insomnia group $(n=103,49 \%$ women $)$ met the criteria in the Diagnostic and Statistical Manual of Mental Disorders, fourth edition, text revision (DSM-IV-TR): difficulty in initiating or maintaining sleep, or nonrestorative sleep, at least three times a week for at least three months (American Psychiatric Association, 2000). The questions regarding the DSM-IVTR criteria were answered via e-mail. In addition, we used the Insomnia Severity Index (Bastien, Vallières, \& Morin, 2001), which is a brief questionnaire that quantifies perceived insomnia severity. We used it in addition to the DSM-IV-TR as a tool to rule out subthreshold insomnia. Therefore, all the selected participants had an ISI score higher than or equal to 15 , which is the cutoff value for clinical insomnia. The mean ISI of the insomnia group was $17.93(\mathrm{SD}=2.23)$. In addition to these criteria, participants were asked the question: "Do you think that you are getting enough sleep?" The goal of this question was to check whether participants perceived their sleep duration as insufficient, which is not something that is directly assessed by the DSM-IV-TR or by the ISI. With regard to the average sleep duration, participants in the insomnia group reported sleeping on average $6.24 \mathrm{hr}$ $(\mathrm{SD}=1.04)$ per night.

The group with voluntary sleep loss $(n=134,43 \%$ women $)$ consisted of young people who spent some of the time normally devoted to sleep on other activities. Since insufficient sleep in young people can be defined as sleeping $6 \mathrm{hr}$ or less per night (Roberts et al., 2011), participants selected in this group reported sleeping on average $5.81 \mathrm{hr}(\mathrm{SD}=0.61)$ per night. The mean ISI score for this group was $10.53(\mathrm{SD}=3.94)$, falling into the category of subthreshold insomnia. However, the relatively high ISI score is explained by the fact that participants with voluntary sleep loss reported not being satisfied with their sleep and experiencing impaired daytime functioning (questions 4-7 of the ISI scale). They did not report any difficulty initiating or maintaining sleep, nor waking up too early (questions 1-3 of the ISI scale), which rules out insomnia as a possible explanation for their sleep loss. Moreover, potential candidates for this group were asked (a) "Do you sleep on average 6 hours or less per night because you prefer to devote more time to other activities?" and (b) "Do you have the feeling that your sleep debt interferes with your daytime functioning (in terms of attention, memory, mood, etc.)?" Only the candidates who answered "yes" to both questions were selected in this group. In addition, the participants were asked (c) "Do you think that you are getting enough sleep?" Only responders who answered "no" were selected. The purpose of the last two questions was to rule out short sleepers who, in spite of sleeping less than $6 \mathrm{hr}$ per night on average, are not actually experiencing a sleep deficit.

In the group of normal sleepers $(n=299,48 \%$ women $)$, we included individuals reporting no significant sleep problems and who said that they were satisfied with the duration and quality of their sleep. Participants had a mean ISI score of $6.17(S D=3.21)$ and an average sleep duration of $7.69 \mathrm{hr}(\mathrm{SD}=0.73)$ per night. All the participants selected in this group answered "yes" to the question "Do you think that you are getting enough sleep?"

\section{Measures}

\section{Behavioral measure}

The Vienna Risk-Taking Test-Traffic (WRBTV) was used to assess the participant's willingness to take risks in potentially dangerous driving situations (Hergovich, Arendasy, Sommer, \& Bognar, 2007). Studies have demonstrated construct, predictive, convergent, and divergent validity, as well as a good internal consistency (Cronbach's $\alpha=0.92$; Arendasy, Hergovich, Sommer, \& Bognar, 2005; Hergovich et al., 2007; Sommer et al., 2008). The Vienna Risk-Taking Test-Traffic is also correlated to sensation seeking and traffic-relevant personality traits (Hergovich et al., 2007). Moreover, this test has been previously used in studies investigating the link between sleep loss and driving (Schwarz et al., 2016). The test consists of 24 videotaped dangerous traffic situations presented from the driver's perspective on a computer screen. The videos were filmed from the inside of the car, enabling participants to easily picture themselves as the driver of the car. These videos include various traffic situations requiring overtaking maneuvers, making speed choices, driving in bad weather or poor sight conditions, and so 
forth. Response latency (in seconds) was recorded as a measure of the person's propensity for risky driving. Specifically, response latency is the time elapsed between the beginning of the video and the moment when the respondent would no longer perform the maneuver because they find it too risky to be carried out. The longer the response latency, the more risk the participant is taking in each traffic situation.

\section{Self-reported measures}

To assess the self-reported alcohol consumption in terms of frequency, we asked participants how often they drank alcohol on a 6-point scale ranging from "never" (1) to "every day" (6). They also reported their drinking habits in terms of quantity (how many drinks they had on average per week).

The Sensation-Seeking Scale (Carton, Lacour, Jouvent, \& Widlocher, 1990; Zuckerman et al., 1964) consists of 72 forced-choice items with 2 possible options. The French version of the Sensation-Seeking Scale was validated by Carton et al. (1990) and comprises 5 factors: the general sensation-seeking factor, thrill and adventure seeking, disinhibition, experience seeking, and boredom susceptibility. The general sensation-seeking factor is based on 22 items (the total score can range from 0 to 22). For example, the participant should choose between option A ("I like to explore a strange city or section of town by myself, even if it means getting lost") and option B ("I prefer a guide when I am in a place I don't know well").Thrill and adventure seeking (14 items, the total score can range from 0 to 14 ) refers to seeking sensations through risky activities, such as extreme sports. The respondent must, for example, choose between (A) "I often wish I could be a mountain climber" and (B) "I can't understand people who risk their necks climbing mountains." Experience seeking (18 items, with a total score ranging from 0 to 18) pertains to the tendency to lead an unconventional lifestyle and to search for new experiences. A typical item is (A) "I am not interested in experience for its own sake" versus (B) "I like to have new and exciting experiences and sensations even if they are a little frightening, unconventional, or illegal." Disinhibition (14 items, with a total score ranging from 0 to 14 ) is characterized by a hedonistic attitude toward life, social disinhibition, and consumption of alcohol and other substances. An example of one such item is (A) "I like 'wild' uninhibited parties" versus (B) "I prefer quiet parties with good conversation." Finally, boredom susceptibility ( 18 items, with a total score ranging from 0 to 18 ) is defined as an aversion for repetitive activities and everything that may be perceived as monotonous. For example, the participant has to choose between (A) "I get bored seeing the same old faces" and (B) "I like the comfortable familiarity of everyday friends."

\section{Procedure}

The research was presented to participants as a study investigating the impact of sleep loss on attention. Participants started with the Vienna Risk-Taking Test-Traffic and then reported their usual alcohol consumption in terms of quantity and frequency. Subsequently, they completed the Sensation-Seeking Scale. All the tests and questionnaires were completed individually and in person, using a computer in an experimental room at our laboratory.

\section{Results}

A one-way ANOVA (Voluntary sleep loss/Insomnia/Normal sleepers) was conducted on ISI scores. The analysis revealed a significant group difference $\left(F[2,246]=413.58, p<.001, \eta_{p}{ }^{2}=.77\right)$. Post-hoc Newman Keuls analyses showed that participants with insomnia scored higher $(M=17.93$, $\mathrm{SD}=2.23)$ than normal sleepers $(\mathrm{M}=6.17, \mathrm{SD}=3.21, \mathrm{p}<.001)$ and participants with voluntary sleep loss $(M=10.53, S D=3.94, p<.001)$. There was also a significant difference between the ISI scores of normal sleepers and individuals with voluntary sleep loss $(p<.001)$.

Regarding risky driving behavior measured with the Vienna Risk-Taking Test-Traffic, a mean latency score (in seconds) for all 24 situations was computed. The mean score varied between 4.52 and 12.76 s $(\mathrm{M}=7.93, \mathrm{SD}=1.44)$. A one-way ANOVA (Voluntary sleep loss/Insomnia/Normal sleepers) 
performed on this score showed a significant group difference $\left(F[2,533]=3.94, p<.05, \eta_{p}^{2}=.015\right)$. Post-hoc Newman Keuls comparisons revealed that participants with voluntary sleep loss had higher risk-taking scores in dangerous driving situations $(\mathrm{M}=8.23, \mathrm{SD}=1.43)$ than participants with insomnia $(M=7.85, S D=1.52, p<.05)$ and normal sleepers $(M=7.82, S D=1.40, p<.05)$, as shown in Figure 1. Although a difference between $8.2 \mathrm{~s}$ and $7.8 \mathrm{~s}$ seems rather small, in the context of driving, for example when overtaking, $0.4 \mathrm{~s}$ may be enough to differentiate a safe maneuver from a risky one. Moreover, a similar range of statistically significant differences between groups has been found in other studies using this test (Hall \& Wiesenthal, 2011). Scores obtained by participants with insomnia and normal sleepers did not differ significantly.

A one-way ANOVA (Voluntary sleep loss/Insomnia/Normal sleepers) was performed on selfreported frequency of alcohol consumption, showing an impact of the group type $(F[2,533]=4.74$, $\left.\mathrm{p}<.01, \mathrm{n}_{\mathrm{p}}{ }^{2}=.017\right)$. Post-hoc Newman Keuls tests indicated that participants with voluntary sleep loss drank alcohol more often $(M=3.91, S D=1.09)$ than participants with insomnia $(M=3.45$, $\mathrm{SD}=1.26, \mathrm{p}<.01)$. However, the difference between participants with voluntary sleep loss and normal sleepers did not reach statistical significance $(M=3.67, S D=1.16, p<.08)$. There was also no difference between individuals with insomnia and normal sleepers.

A one-way ANOVA (Voluntary sleep loss/Insomnia/Normal sleepers) revealed a significant difference in the self-reported average number of drinks per week $(F[2,533]=12.45, p<.001$, $\left.\eta_{\mathrm{p}}{ }^{2}=.045\right)$. Post-hoc Newman Keuls analyses showed that participants with voluntary sleep loss consumed more drinks per week $(\min =0, \max =35, \mathrm{M}=4.95, \mathrm{SD}=5.82)$ than participants with insomnia $(\min =0, \max =13, \mathrm{M}=2.92, \mathrm{SD}=3.25, \mathrm{p}<.001)$ and normal sleepers $(\min =0$, $\max =25, M=2.93, S D=3.26, p<.001$ ) (Figure 2). No significant difference between individuals with insomnia and normal sleepers was found.

Given that participants with voluntary sleep loss are getting, on average, slightly less sleep than participants with insomnia, it was important to check whether the differences between groups were due to the origin of sleep loss and not to a difference in sleep duration. ANCOVA analyses were conducted with the origin of sleep loss (Voluntary sleep loss/Insomnia/Normal sleepers) as between-subjects factor and self-reported sleep duration as a covariate. The ANCOVA performed on risky driving behavior revealed no effect of the origin of sleep loss ( $F$ $\left.[2,532]=1.65, \mathrm{~ns}, \eta_{\mathrm{p}}{ }^{2}=.006\right)$, or sleep duration $\left(\mathrm{F}[1,532]=.98, \mathrm{~ns}, \mathrm{\eta}_{\mathrm{p}}{ }^{2} \cdot=.002\right)$. The ANCOVA conducted on the frequency of alcohol consumption yielded an effect of the origin of sleep loss $\left(\mathrm{F}[2,532]=4.30, \mathrm{p}<.05, \mathrm{\eta}_{\mathrm{p}}{ }^{2}=.016\right)$, but no effect of sleep duration $(\mathrm{F}[1,532]=.94$, ns, $\left.\eta_{\mathrm{p}}{ }^{2}=.002\right)$. Similarly, the ANCOVA performed on the weekly number of drinks showed an effect

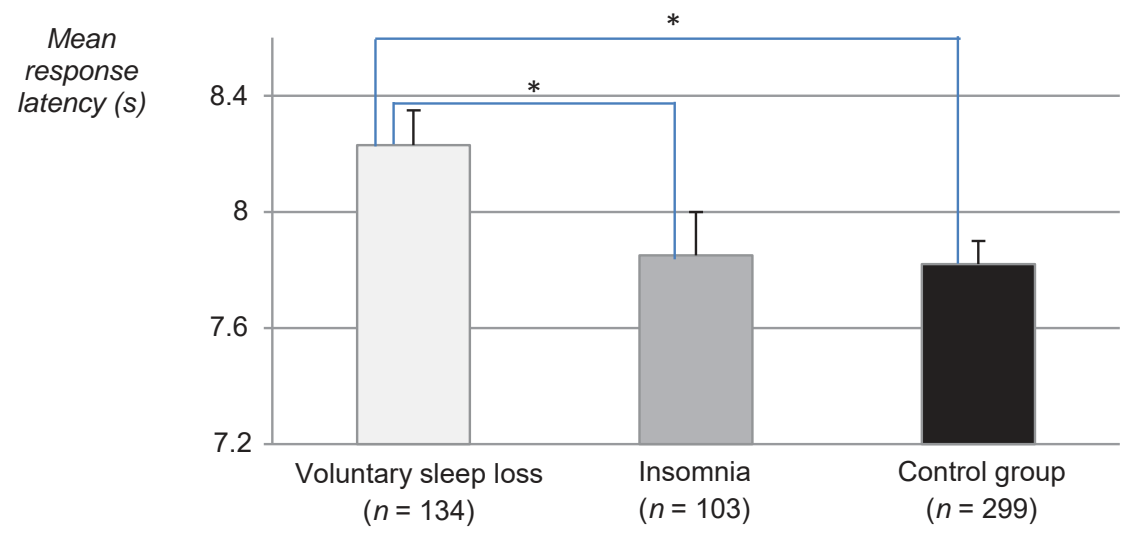

Figure 1. Risky driving behavior. Risky driving behavior was measured with the Vienna Risk-Taking Test-Traffic. Higher latencies indicate greater risk taking in dangerous driving situations. A mean score was computed based on the response latencies for the 24 different driving situations. Error bars represent the standard error of the mean. ${ }^{*} p<.05$. 


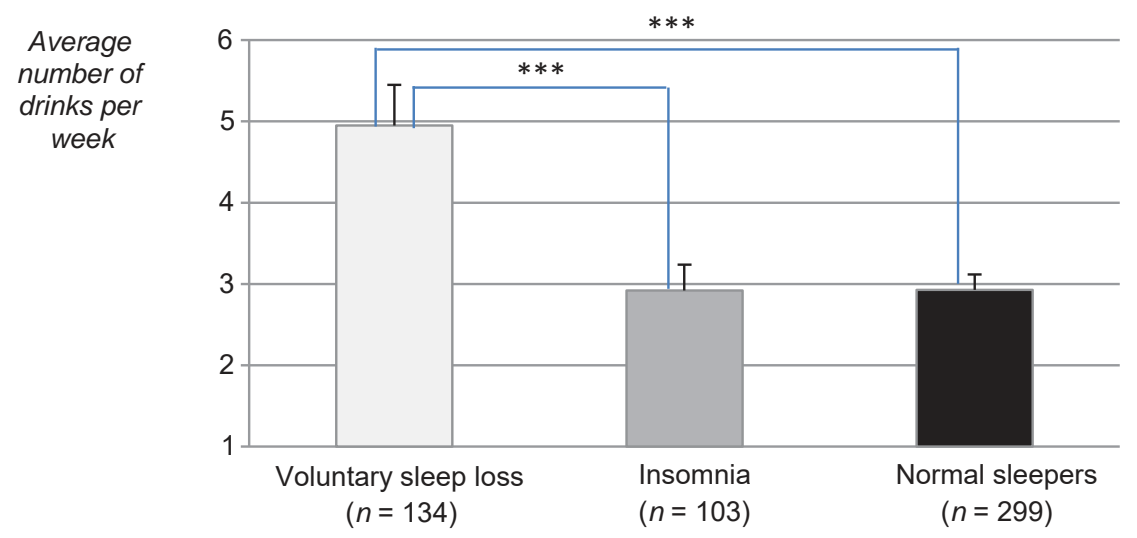

Figure 2. Alcohol consumption. Error bars represent the standard error of the mean. ${ }^{* * *} p<.001$.

of the origin of sleep loss $\left.F[2,532]=8.98, p<.001, \eta_{p}{ }^{2}=.033\right)$, but no effect of sleep duration $(F$ $\left.[1,532]=.08, \mathrm{~ns}, \mathrm{\eta}_{\mathrm{p}}{ }^{2}=.00\right)$. These analyses confirm that the differences in drinking behavior found between groups are due to the origin of sleep loss and not to differences in sleep duration.

With regard to sensation seeking, a one-way ANOVA (Voluntary sleep loss/Insomnia/Normal sleepers) yielded a significant group difference for the general factor of the Sensation-Seeking Scale $\left(F(2,532)=3.40, p<.05, \eta_{p}^{2}=.034\right)$. Post-hoc Newman Keuls analyses showed that participants with voluntary sleep loss tended to have a higher propensity for sensation seeking $(\mathrm{M}=12.98$, $\mathrm{SD}=4.01)$ than normal sleepers $(\mathrm{M}=11.93, \mathrm{SD}=3.81, \mathrm{p}<.06)$. The group with insomnia $(M=12.33, S D=4.04)$ was intermediate and did not differ significantly from the group with voluntary sleep loss, nor from the normal sleepers.

One-way ANOVAs were performed to determine group differences (Voluntary sleep loss/ Insomnia/Normal sleepers) on the four subscales of the Sensation-Seeking Scale. Analyses revealed a significant group difference on the Disinhibition score $(F[2,532]=7.83, p<.001$, $\left.\eta_{\mathrm{p}}{ }^{2}=.029\right)$. Post-hoc Newman Keuls tests indicated that participants with voluntary sleep loss had a higher Disinhibition score $(M=6.49, S D=2.87)$ than those with insomnia $(M=5.56$, $\mathrm{SD}=2.84, \mathrm{p}<.01)$ and normal sleepers $(\mathrm{M}=5.41, \mathrm{SD}=2.47, \mathrm{p}<.01)$, as shown in Figure 3. There was no significant difference between participants with insomnia and normal sleepers. The scores obtained for the other subscales of the Sensation-Seeking Scale (thrill and adventure seeking, experience seeking, boredom susceptibility) did not differ across the three groups.

ANCOVA analyses were conducted with the origin of sleep loss (Voluntary sleep loss/Insomnia/Normal sleepers) as between-subjects factor and the Sensation-Seeking general factor as a covariate. The ANCOVA performed on risky driving behavior showed an effect of the origin of sleep loss $(F[2,531]=3.43, p<.05$, $\left.\eta_{\mathrm{p}}{ }^{2}=.013\right)$, but no effect of the sensation seeking $\left(\mathrm{F}[1,531]=2.36, \mathrm{~ns}, \mathrm{\eta}_{\mathrm{p}}^{2}=.004\right)$. In contrast, the ANCOVA conducted on the frequency of alcohol consumption revealed an effect of the origin of sleep loss $\left(F[2,531]=3.88, p<.05, \eta_{p}^{2}=.014\right)$, as well as an effect of sensation seeking $(F[1,531]=67.07, p<.001$, $\left.\eta_{\mathrm{p}}^{2}=.112\right)$. Similarly, the ANCOVA performed on the weekly number of drinks yielded an effect of the origin of sleep loss $\left(F[2,531]=9.85, \mathrm{p}<.001, \mathrm{\eta}_{\mathrm{p}}{ }^{2}=.036\right)$ and an effect of sensation seeking $(\mathrm{F}[1,531]=63.88$, $\left.\mathrm{p}<.001, \mathrm{n}_{\mathrm{p}}^{2}=.107\right)$.

\section{Discussion}

Our findings show that the origin of sleep loss does indeed matter in the link between sleep loss and risk taking. Compared to normal sleepers and participants with insomnia, participants with voluntary sleep loss take more risks in virtual driving situations. They also report drinking two more 


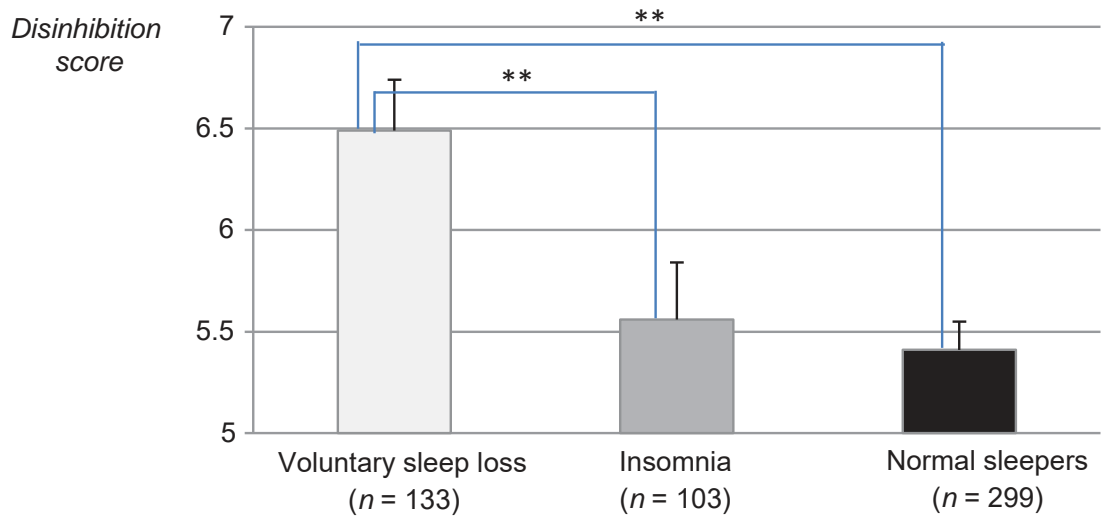

Figure 3. Sensation seeking (disinhibition subscale). Higher scores indicate a higher tendency toward disinhibition. Error bars represent the standard error of the mean. ${ }^{* *} p<.01$.

drinks on average per week than normal sleepers and participants with insomnia, which could make them more likely to face the negative consequences of alcohol consumption. However, when it comes to the frequency of drinking, the differences between groups are quite low, suggesting that it is the quantity of alcohol rather than the frequency of consumption that differentiates our groups. With regard to sensation seeking, we found that the group with voluntary sleep loss exhibits higher disinhibition scores on the sensation-seeking scale than the other two groups. This suggests that young people with voluntary sleep loss are more likely to seek experiences associated with risk and disinhibition, for example binge drinking, drunk driving, excessive speeding, or extreme sports (Slanger \& Rudestam, 1997; Zuckerman, 1994).

The finding that participants with voluntary sleep loss take more risks than normal sleepers can be explained by two mechanisms. Firstly, this might be due to differences in terms of personality. This explanation is in line with our data showing that, in comparison to the other two groups, participants who voluntarily decrease sleep duration have higher disinhibition scores on the sensation-seeking scale. So far, the role of personality in the link between sleep loss and risk taking has often been neglected in the literature. But our analyses using sensation seeking as a covariate show that sensation seeking is an important factor to consider in the link between sleep loss and risk taking. Due to the correlational nature of the data, however, it remains unclear whether sensation seeking leads to voluntary sleep loss and risk-taking behavior, or whether these different phenomena simply occur at the same time. To achieve a better understanding of the role of the personality factors associated with voluntary sleep loss, a broader investigation of personality, for example, based on the Big Five (Goldberg, 1990), should be conducted.

One limitation of this study is that we did not consider sleep opportunity when we selected participants in the group with voluntary sleep loss. We employed the term voluntary based on the fact that the sleep loss was not caused by a sleep disorder, but was a result of doing other activities instead of sleeping, regardless of the nature of these activities (work commitments vs. leisure). It would be interesting to conduct further research to investigate the role of sleep opportunity. We expect that participants who lack sleep for leisure-related reasons may have a higher propensity for sensation seeking and may be more inclined to drink alcohol and take driving risks than participants who lack sleep because of work or study commitments.

A second mechanism that may explain why participants with voluntary sleep loss take more risks than normal sleepers is that, in addition to personality differences, sleep loss in itself may lead to higher risk taking. Increased risk taking as a consequence of sleep loss has been indeed demonstrated in many experimental studies (Davis, Avis, \& Schwebel, 2013; Frings, 2012; Killgore, Balkin, \& Wesensten, 2006; 
Killgore, Kamimori, \& Balkin, 2011). But in that case, why is it that participants with insomnia do not take more risks than normal sleepers despite having insufficient sleep? Perhaps, given that people suffering from insomnia are typically more anxious (Chauvin et al., 2015; Jansson-Fröjmark \& Lindblom, 2008; Morphy, Dunn, Lewis, Boardman, \& Croft, 2007), their anxiety may override the inclination for risky behavior that could have been induced by the sleep loss. There is in fact a large body of literature showing that anxiety is associated with risk aversion (Maner et al., 2007) and with an increased vigilance to threat-related stimuli (Mathews, 1990).

In addition, people who suffer from insomnia might develop compensatory strategies as a means to overcome the impairments caused by sleep loss. It has been suggested that people who lack sleep often mobilize more attentional resources in order to compensate for their daytime sleepiness or fatigue (Hockey, Wastell, \& Sauer, 1998). A good example has been reported in nontreated patients with apnea: Although in an experimental setting these patients typically show an impaired performance in monotonous driving conditions, it has been shown that, in real-life conditions, not only do they drive at nearnormal level, but also they display more cautious behavior than the control group (Tassi et al., 2008). This could be the result of making a greater effort to stay awake, as suggested by increased beta activity in their waking EEG. It is possible that similar compensatory processes occur in patients with insomnia.

Another possibility is that participants with insomnia could be actually getting more sleep than they think. A discrepancy between subjective (e.g., measured by questionnaire) and objective sleep duration (e.g., measured by polysomnography or actigraphy) has been reported in the literature. In contrast with normal sleepers who tend to overestimate their sleep duration (Matthews et al., in press), people with insomnia usually report less sleep time than their objectively measured sleep time (Kay, Buysse, Germain, Hall, \& Monk, 2015).

The findings of the present study should also be discussed in the light of the extensive literature on the cognitive dysfunctions related to sleep loss. It has been consistently demonstrated that sleep loss impairs cognitive functions (Alhola \& Polo-Kantola, 2007; Killgore, 2010) and emotional regulation (Baum et al., 2014; Brand et al., 2016; Mauss, Troy, \& LeBourgeois, 2013). It is therefore reasonable to assume that sleep deficit can lead to biased risk perception as well as to insufficient inhibition of risky and impulsive behaviors. From a neuroanatomical point of view, sleep loss has been shown to impair the functioning of the prefrontal cortex (Harrison \& Horne, 2000; Thomas et al., 2000; Womack, Hook, Reyna, \& Ramos, 2013). The prefrontal cortex plays a major role in the processes involved in risk taking, such as risk perception, inhibition of impulsive behavior, decision making, and so forth (Spear, 2000; Steinberg, 2007). As a result of sleep loss, the prefrontal cortex could therefore be less effective in accomplishing its regulating role in risk taking. Further research should be carried out to investigate the role played by the prefrontal cortex, for example, by using functional imagery on participants with voluntary versus involuntary sleep loss while performing risk-related tasks.

Further studies should also be conducted to provide more insight into the relative contribution of personality traits and sleep loss in the increased risk-taking found in young people with voluntary sleep loss. For example, it could be interesting to carry out an experimental study to investigate how people with chronic voluntary sleep loss are impacted by different degrees of experimentally induced sleep deprivation.

With regard to real-world implications, our main finding is that young people who deliberately adopt a lifestyle of insufficient sleep appear to be a high-risk category: They are more inclined toward sensation seeking, drink larger quantities of alcohol, and take more risks when they drive. Thus they appear to be even more at risk than the rest of the young population of facing the dangerous consequences of alcohol abuse or of being involved in a traffic accident.

\section{Funding}

This work was supported by the MAIF Foundation, France (Convention N ${ }^{\circ}$ 2012-05). The MAIF Foundation had no involvement in the collection, analysis and interpretation of the data, nor in the writing of the manuscript and in the decision to submit it for publication. 


\section{References}

Alhola, P., \& Polo-Kantola, P. (2007). Sleep deprivation: Impact on cognitive performance. Neuropsychiatric Disease and Treatment, 3(5), 553-567.

American Psychiatric Association. (2000). DSM-IV-TR: Manuel diagnostique et statistique des troubles mentaux (4e éd.). Paris, France: Masson.

Arendasy, M. E., Hergovich, A., Sommer, M., \& Bognar, B. (2005). Dimensionality and construct validity of a videobased, objective personality test for the assessment of willingness to take risks in road traffic. Psychological Reports, 97(1), 309-320. doi:10.2466/pr0.97.1.309-320

Arnett, J. (1992). Reckless behavior in adolescence: A developmental perspective. Developmental Review, 12(4), $339-373$. doi:10.1016/0273-2297(92)90013-R

Assailly, J. P. (2001). Sur la route, les conduites à risque... Revue Toxibase, 2(6), 1-15.

Ball, S. A., Carroll, K. M., \& Rounsaville, B. J. (1994). Sensation seeking, substance abuse, and psychopathology in treatment-seeking and community cocaine abusers. Journal of Consulting and Clinical Psychology, 62(5), 1053-1057. doi:10.1037/0022-006X.62.5.1053

Bastien, C. H., Vallières, A., \& Morin, C. M. (2001). Validation of the Insomnia Severity Index as an outcome measure for insomnia research. Sleep Medicine, 2(4), 297-307. doi:10.1016/S1389-9457(00)00065-4

Baum, K. T., Desai, A., Field, J., Miller, L. E., Rausch, J., \& Beebe, D. W. (2014). Sleep restriction worsens mood and emotion regulation in adolescents. Journal of Child Psychology and Psychiatry, 55(2), 180-190. doi:10.1111/jcpp.12125

Brand, S., Kirov, R., Kalak, N., Gerber, M., Schmidt, N. B., Lemola, S., . . . Holsboer-Trachsler, E. (2016). Poor sleep is related to lower emotional competence among adolescents. Behavioral Sleep Medicine, 14(6), 602-614. doi:10.1080/ 15402002.2015.1048450

Carskadon, M. A. (1990). Patterns of sleep and sleepiness in adolescents. Pediatrician, 17(1), 5-12.

Carton, S., Lacour, C., Jouvent, R., \& Widlocher, D. (1990). Le concept de recherche de sensations: Traduction et validation de l'échelle de Zuckerman. Psychiatrie Et Psychobiologie, 5(1), 39-48.

Catrett, C. D., \& Gaultney, J. F. (2009). Possible insomnia predicts some risky behaviors among adolescents when controlling for depressive symptoms. The Journal of Genetic Psychology, 170(4), 287-309. doi:10.1080/00221320903218331

Chauvin, B., Thibault-Stoll, A., Chassagnon, S., Biry, S., Petiau, C., \& Tassi, P. (2015). Sleep-related cognitions mediate the impact of neuroticism on insomnia. American Journal of Health Behavior, 39(5), 623-631. doi:10.5993/AJHB.39.5.4

Dahl, R. E., \& Lewin, D. S. (2002). Pathways to adolescent health sleep regulation and behavior. Journal of Adolescent Health, 31(6, Supplement), 175-184. doi:10.1016/S1054-139X(02)00506-2

Davis, A. L., Avis, K. T., \& Schwebel, D. C. (2013). The effects of acute sleep restriction on adolescents' pedestrian safety in a virtual environment. Journal of Adolescent Health, 53(6), 785-790. doi:10.1016/j.jadohealth.2013.07.008

Deery, H. A. (1999). Hazard and risk perception among young novice drivers. Journal of Safety Research, 30(4), $225-236$. doi:10.1016/S0022-4375(99)00018-3

ESPAD. (2015). European school survey project on alcohol and other drugs 2015 report. Retrieved from http://www. espad.org/report/summary

Frings, D. (2012). The effects of sleep debt on risk perception, risk atraction and betting behavior during a blackjack style gambling task. Journal of Gambling Studies, 28(3), 393-403. doi:10.1007/s10899-011-9266-9

Gibson, E. S., Powles, A. C., Thabane, L., O’Brien, S., Molnar, D. S., Trajanovic, N., ... Chilcott-Tanser, L. (2006). "Sleepiness" is serious in adolescence: Two surveys of 3235 Canadian students. BMC Public Health, 6, 116-125. doi:10.1186/1471-2458-6-116

Goldberg, L. R. (1990). An alternative "description of personality": The big-five factor structure. Journal of Personality and Social Psychology, 59(6), 1216-1229. doi:10.1037/0022-3514.59.6.1216

Guénolé, F., Louis, J., \& Nicolas, A. (2008). Troubles du sommeil et violence chez les adolescents. Neuropsy News, 7, 71-75.

Hall, A., \& Wiesenthal, D. L. (2011). The effects of music tempo on driver risk taking. Paper presented at the 21st Canadian Multidisciplinary Road Safety Conference. https://yorkcomputertechnologies.com/pdfs/Hall2011.pdf

Harrison, Y., \& Horne, J. A. (2000). The impact of sleep deprivation on decision making: A review. Journal of Experimental Psychology: Applied, 6(3), 236-249.

Hergovich, A., Arendasy, M. E., Sommer, M., \& Bognar, B. (2007). The vienna risk-taking test-traffic. A new measure of road traffic risk-taking. Journal of Individual Differences, 28(4), 198-204. doi:10.1027/1614-0001.28.4.198

Hingson, R. W., Heeren, T., Zakocs, R. C., Kopstein, A., \& Wechsler, H. (2002). Magnitude of alcohol-related mortality and morbidity among U.S. college students ages 18-24. Journal of Studies on Alcohol, 63(2), 136-144. doi:10.15288/jsa.2002.63.136

Hockey, G. R. J., Wastell, D. G., \& Sauer, J. (1998). Effects of sleep deprivation and user interface on complex performance: A multilevel analysis of compensatory control. Human Factors, 40(2), 233-253. doi:10.1518/001872098779480479

Hysing, M., Pallesen, S., Stormark, K. M., Jakobsen, R., Lundervold, A. J., \& Sivertsen, B. (2015). Sleep and use of electronic devices in adolescence: Results from a large population-based study. BMJ Open, 5(1). doi:10.1136/bmjopen-2014-006748

Hysing, M., Pallesen, S., Stormark, K. M., Lundervold, A. J., \& Sivertsen, B. (2013). Sleep patterns and insomnia among adolescents: A population-based study. Journal of Sleep Research, 22(5), 549-556. doi:10.1111/jsr.2013.22.issue-5 
Jansson-Fröjmark, M., \& Lindblom, K. (2008). A bidirectional relationship between anxiety and depression, and insomnia? A prospective study in the general population. Journal of Psychosomatic Research, 64(4), 443-449. doi:10.1016/j.jpsychores.2007.10.016

Kay, D. B., Buysse, D. J., Germain, A., Hall, M., \& Monk, T. H. (2015). Subjective-Objective sleep discrepancy among older adults: Associations with insomnia diagnosis and insomnia treatment. Journal of Sleep Research, 24(1), 32-39. doi:10.1111/jsr.2015.24.issue-1

Killgore, W. D. S. (2010). Effects of sleep deprivation on cognition. In G. Kerkhof \& H. Van Dongen (Eds.), Progress in brain research (Vol. 185, pp. 105-129). Oxford, UK.

Killgore, W. D. S., Balkin, T. J., \& Wesensten, N. J. (2006). Impaired decision making following 49 h of sleep deprivation. Journal of Sleep Research, 15(1), 7-13. doi:10.1111/j.1365-2869.2006.00487.x

Killgore, W. D. S., Kamimori, G. H., \& Balkin, T. J. (2011). Caffeine protects against increased risk-taking propensity during severe sleep deprivation. Journal of Sleep Research, 20(3), 395-403. doi:10.1111/j.1365-2869.2010.00893.x

Maner, J. K., Richey, J. A., Cromer, K., Mallott, M., Lejuez, C. W., Joiner, T. E., \& Schmidt, N. B. (2007). Dispositional anxiety and risk-avoidant decision-making. Personality and Individual Differences, 42(4), 665-675. doi:10.1016/j.paid.2006.08.016

Mathews, A. (1990). Why worry? The cognitive function of anxiety. Behaviour Research and Therapy, 28(6), 455-468. doi:10.1016/0005-7967(90)90132-3

Matthews, K. A., Patel, S. R., Pantesco, E. J., Buysse, D. J., Kamarck, T. W., Lee, L., \& Hall, M. H. (in press). Similarities and differences in estimates of sleep duration by polysomnography, actigraphy, diary, and self-reported habitual sleep in a community sample. Sleep Health, 4(1), 96-103. doi:10.1016/j.sleh.2017.10.011

Mauss, I. B., Troy, A. S., \& LeBourgeois, M. K. (2013). Poorer sleep quality is associated with lower emotion-regulation ability in a laboratory paradigm. Cognition and Emotion, 27(3), 567-576. doi:10.1080/02699931.2012.727783

Millman, R. P. (2005). Excessive sleepiness in adolescents and young adults: Causes, consequences, and treatment strategies. Pediatrics, 115(6), 1774-1786. doi:10.1542/peds.2005-0772

Morphy, H., Dunn, K. M., Lewis, M., Boardman, H. F., \& Croft, P. R. (2007). Epidemiology of insomnia: A longitudinal study in a UK population. Sleep, 30(3), 274-280.

National Sleep Foundation. (2006). Summary of findings: 2006 sleep in America poll. Retrieved from http://www. sleepfoundation.org/sites/default/files/2006_summary_of_findings.pdf

O’Brien, E. M., \& Mindell, J. A. (2005). Sleep and risk-taking behavior in adolescents. Behavioral Sleep Medicine, 3(3), 113-133. doi:10.1207/s15402010bsm0303_1

Reynolds, C. M., Gradisar, M., Kar, K., Perry, A., Wolfe, J., \& Short, M. A. (2015). Adolescents who perceive fewer consequences of risk-taking choose to switch off games later at night. Acta Paediatrica, 104(5), e222-e227. doi:10.1111/apa.2015.104.issue-5

Roberts, R. E., Roberts, C. R., \& Xing, Y. (2011). Restricted sleep among adolescents: Prevalence, incidence, persistence, and associated factors. Behavioral Sleep Medicine, 9(1), 18-30. doi:10.1080/15402002.2011.533991

Schwarz, J. F. A., Geisler, P., Hajak, G., Zulley, J., Rupprecht, R., Wetter, T. C., \& Popp, R. F. J. (2016). The effect of partial sleep deprivation on computer-based measures of fitness to drive. Sleep \& Breathing, 20(1), 285-292. doi:10.1007/s11325-015-1220-0

Slanger, E., \& Rudestam, K. E. (1997). Motivation and disinhibition in high risk sports: Sensation seeking and selfefficacy. Journal of Research in Personality, 31(3), 355-374. doi:10.1006/jrpe.1997.2193

Sommer, M., Herle, M., Häusler, J., Risser, R., Schützhofer, B., \& Chaloupka, C. (2008). Cognitive and personality determinants of fitness to drive. Transportation Research Part F: Traffic Psychology and Behaviour, 11(5), 362-375.

Spear, L. P. (2000). The adolescent brain and age-related behavioral manifestations. Neuroscience \& Biobehavioral Reviews, 24(4), 417-463. doi:10.1016/S0149-7634(00)00014-2

Steinberg, L. (2007). Risk taking in adolescence: New perspectives from brain and behavioral science. Current Directions in Psychological Science, 16(2), 55-59. doi:10.1111/j.1467-8721.2007.00475.x

Strauch, I., \& Meier, B. (1988). Sleep need in adolescents: A longitudinal approach. Sleep: Journal of Sleep Research \& Sleep Medicine, 11(4), 378-386. doi:10.1093/sleep/11.4.378

Tassi, P., Grenèche, J., Pebayle, T., Eschenlauer, A., Hoeft, A., Bonnefond, A., .. Muzet, A. (2008). Are OSAS patients impaired in their driving ability on a circuit with medium traffic density? Accident Analysis \& Prevention, 40(4), 1365-1370. doi:10.1016/j.aap.2008.02.007

Thomas, M., Sing, H., Belenky, G., Holcomb, H., Mayberg, H., Dannals, R., .. Redmond, D. (2000). Neural basis of alertness and cognitive performance impairments during sleepiness. I. Effects of $24 \mathrm{~h}$ of sleep deprivation on waking human regional brain activity. Journal of Sleep Research, 9(4), 335-352. doi:10.1046/j.1365-2869.2000.00225.x

Van den Bulck, J. (2007). Adolescent use of mobile phones for calling and for sending text messages after lights out: Results from a prospective cohort study with a one-year follow-up. Sleep, 30(9), 1220-1223. doi:10.1093/sleep/30.9.1220

Vignau, J., Bailly, D., Duhamel, A., Vervaecke, P., Beuscart, R., \& Collinet, C. (1997). Epidemiologic study of sleep quality and troubles in French secondary school adolescents. Journal of Adolescent Health, 21(5), 343-350. doi:10.1016/S1054-139X(97)00109-2

Wolfson, A. R., \& Carskadon, M. A. (1998). Sleep schedules and daytime functioning in adolescents. Child Development, 69(4), 875-887. doi:10.1111/j.1467-8624.1998.tb06149.x 
Womack, S. D., Hook, J. N., Reyna, S. H., \& Ramos, M. (2013). Sleep loss and risk-taking behavior: A review of the literature. Behavioral Sleep Medicine, 11(5), 343-359. doi:10.1080/15402002.2012.703628

Zuckerman, M. (1994). Behavioral expressions and biosocial bases of sensation seeking. New York, NY: Cambridge University Press.

Zuckerman, M., Kolin, E. A., Price, L., \& Zoob, I. (1964). Development of a sensation-seeking scale. Journal of Consulting Psychology, 28(6), 477-482. doi:10.1037/h0040995

Zuckerman, M., \& Neeb, M. (1980). Demographic influences in sensation seeking and expressions of sensation seeking in religion, smoking and driving habits. Personality and Individual Differences, 1(3), 197-206. doi:10.1016/0191$8869(80) 90051-3$ 